\title{
Impact of Infrastructure on Productivity of Small and Medium Enterprises in Nigeria
}

\author{
Anthony E. Hassan $(\mathrm{PhD})^{1 *} \quad$ Dr Kashim Akor ${ }^{2} \quad$ Emmanuel O. Bamiduro ${ }^{2}$ \\ 1. Department of Economics, University of Abuja, Abuja, Nigeria \\ 2. National Productivity Center, Abuja, Nigeria
}

\begin{abstract}
The study investigates the link between infrastructure and productivity of small and medium enterprises (SMEs) in Nigeria Following the Engle and Granger two-step approach to cointegration and employing quarterly time series for the Nigerian economy over the period 1980 to 2017 . We found long-run equilibrium relationship between infrastructure and small and medium enterprises output in Nigeria over the period investigated. Particularly, electricity infrastructure impacted most negatively and significantly on SMEs output with a unit change in electricity output causing SMEs output to drop by about 0.2 units in the short run. The contribution of water resources and transport infrastructure have not been significant on SMEs productivity. The error correcting term indicates that about 7.33E-09 of the disequilibrium between selected infrastructure and SMEs output in the economy is being restored annually. The conclusion is that the output of SMEs in the country has been constrained by infrastructure gap and this has limited the growth capacity of the Nigerian economy. Policies that will ensure that the SMEs play their roles in the economy must be hatched. In addition, the government, in collaboration with relevant stakeholders may consider creating SMEs zones in every State of the country and provide needed infrastructure within the zone such that SMEs can enjoy economies of agglomeration.
\end{abstract}

Keywords: Infrastructure, SMEs, Economic growth, Employment, Wealth creation

JEL H54

DOI: $10.7176 /$ RHSS/9-2-05

\section{Introduction}

Small and medium scale enterprises (SMEs) are to an economy as enzymes are to human body. They are generally adjudged vital for economic growth and promotion of job opportunities within an economy Okhankhuele, (2017). Usually, the larger percentage of the populace in every economy are found to be operating in one form of Small and Medium Enterprise (SMEs) or the other ranging from farmers, artisans to micro manufacturing unit for varieties of household products and services. SMEs represent a veritable vehicle for the achievement of national economic objectives of employment generation and poverty reduction as well as the development of entrepreneurial capabilities.

According to the National bureau of Statistics (NBS) Small and Medium Enterprises comprise about 87\% of the economy (Ogbuanu, Kabuoh and Okwu, 2014). SMEs contribute about 50\% to the nation's Gross Domestic Product (Evbuomwan, Ikpi, Okoruwa, and Akinyosoye, 2012). Averagely, SMEs represent above $90 \%$ of the enterprises and make up 50 to $60 \%$ of employment in lots of African countries. Nigeria SMEs make available around $50 \%$ of all the jobs and enable our natural resources to be utilized due to their high innovativeness. This contributes to raise the wealth of the nation via higher productivity (Ogbuanu et al., 2014). They have aided in enhancing the standard of living of a lot of people, particularly those leaving in the rural areas.

The World Bank estimates that every $1 \%$ of government funds spent on infrastructure leads to about 1-2 percent point increase in Gross Domestic Product (GDP), which invariably means that there is a correlation between infrastructure development and economic growth, most especially through SMEs. Hence the importance of infrastructure in the Nation's economy cannot be underplayed.

This accounts for the efforts of government at various levels (local, state and Federal) at channeling resources and formulating policies aimed at facilitating growth, development and performance of SMEs through infrastructure investments and specialised financial institutions. The government in its development plan has proposed that Nigeria would be among the top 20 economies in the world by the year 2020 . In order to achieve this objective, Infrastructural development has received some level of attention since independence in the country. Nevertheless, it is doubtful if the current stock of infrastructure is sufficient for the SMEs to leverage upon in order to bring about the much needed socio-economic development in the country. There is therefore the need to evaluate the impact of the present infrastructure stock on SMEs productivity and on the overall growth of the Nigerian economy.

The provision of infrastructure services to meet the demands of businesses-both small and medium scale, is one of the major challenges of economic development in developing economies like Nigeria. To this effect, Small and Medium Enterprises (SMEs) in Nigeria have not been able to live up to expectation in relation to spurring economic growth and development in the Nigerian economy. The SMEs in Nigeria operate in an 
environment with very poor infrastructure which constitutes barrier to their emergence and growth of the existing ones, hindering international competitiveness. In many States in the country, nonexistence of infrastructure, inability to access market, inadequate power and water facilities constitute one of the major problems militating against the productivity and sustainable development of SMEs.

SMEs require one form of infrastructure or the other as basic input, without which they cannot operate and if they must, they will have to provide such infrastructure themselves. This affect the unit cost of production, selling prices of their product or services, turnover and profit. Here lies the bane of most SMEs in many developing economies battling with infrastructure deficit. Accordingly, the potentials inherent in the SME are generally believed to have been constrained by lack of or weak infrastructure base in the Nigerian economy. This is believed to be a factor in the dwindling productivity of these all important economic growth engine and the backlash include low economic growth, poverty and high rate of youth unemployment in the Nigerian economy. Infrastructure is critical to SMEs output supply chain. For instance, inadequate electricity can limit production capacity, poor transportation network and communication have the tendency to constraint value addition and market frontier for most SMEs. In addition, infrastructure inadequacy can jeopardise SMEs sustainability as many SMEs may quit because of high cost of improvising and competition from imported goods. This article is organized into six sections. The preceding was introduction and background and it is followed by review of some relevant literature, theoretical frame, methodology, model specification, estimation and discussion of result, and conclusion in that order.

\section{Review of Literature}

There are a number of studies done in respect of the role of infrastructure in promoting economic growth in developed economies. The findings from such studies have led to the call for developing countries to invest more in infrastructure in order for them to attain the much needed growth in the face of falling welfare as measured by poverty rate, non-access to basic social and economic facilities among other available development indexes. For instance, Auscher, (1989) shows that infrastructure gap accounts for the difference between the developed and developing economies. The study by Auscher actually opens up the research space on the role of infrastructure in promoting growth and development in any economy.

The study by (Vivien \& Nataliya, 2011), suggests that infrastructure was responsible for a net contribution of around one percentage point to Nigeria's per capita growth performance in recent years, in spite of the fact that unreliable power supplies held growth back. They suggested that raising the country's infrastructure endowment to that of the region's middle-income countries could boost annual growth by around four (4) percentage points.

Another study was conducted by (Canning \& Pedroni, 1999) to test causality between investments in three types of infrastructure; that is, kilometers of paved road, kilowatts of electricity generating capacity, and number of telephones based on data from a panel of 67 countries between 1960 and 1990. Strong evidence in favour of causality running in both directions between each of the three infrastructure variables and GDP among a significant number of the countries investigated. Accordingly, they suggested more investment in these infrastructures since they have the potential to influence economic growth. Moreover, they submitted that countries need to package sound macroeconomic policies that target higher economic growth. The finding in relation to electricity GDP feedback effect portrays great hope for SMEs, particularly as SMEs outputs have the potential to feature prominently in the GDP.

A study on infrastructure investment and economic growth in South Africa by (Wolassa, 2012) from 1960 to 2009 used bi-variate vector auto regression (VAR) model with and without a structural break. The result indicates that there is a strong causality between economic infrastructure investment and GDP growth that runs in both directions implying that economic infrastructure investment drives the long term economic growth in South Africa while improved growth feeds back into more public infrastructure investments. This finding further confirms the submission of (Canning \& Pedroni, 1999) with respect to the need to expand infrastructure access and promotion of productivity in an economy.

Another study explores the relationship between infrastructure and economic growth by including the data of expenditure in infrastructure as a share of GDP in traditional growth cross-country regressions (SanchezRobles, 1998). The results were, however, inconclusive but elaborated some new indicators of investment in infrastructure employing physical units of infrastructure. He found positive and significant correlation with growth in two different samples of countries. The policy suggested was for countries to pay closer attention to physical infrastructure provided as against the quantum of budgetary expenditure on infrastructure as this may be misleading.

The Fisher's tests of Pesaran, Shin and Smith was used to conduct a study in South Africa. The study finds causation between infrastructure and economic growth (Perkins et al, 2005). They identified long-run relationships from public-sector economic infrastructure investment and fixed capital stock to gross domestic product (GDP), from roads to GDP and from GDP to a range of other types of infrastructure. They also 
established that the relationship between economic infrastructure and economic growth run in both directions and conclude that policies aimed at attracting investment in infrastructure and promotion of economic growth can greatly improve the welfare of the people.

Okhankhuele, (2017) examined the effect of small and medium scale enterprises on economic growth in Nigeria using data over 1882 to 2012 using Pearson Product-Moment Correlation Coefficient (PPMCC). He recognised SMEs as source of economic growth in Nigeria as he found a significant and positive relationship between SME's contribution to Nigeria's Gross Domestic Product (GDP) and Nigeria's GDP. Policy relevance from this study is that Government needs to make policies towards the development of SMEs in order to make them serve as the source of economic growth in Nigeria.

Thorsten \& Demirguc-Kunt (2006) examined access to finance by small and medium-size enterprises (SMEs). Their study posits that substantial evidence points to the fact that SMEs face growth constraints and have less access to formal sources of external finance, potentially explaining the reason for low SMEs' contribution to growth. Financial and institutional development helps alleviate SMEs' growth constraints and increase their access to external finance and thus levels the playing field between firms of different sizes. Specific financing tools such as leasing and factoring can be useful in facilitating greater access to finance even in the absence of well-developed institutions, as can systems of credit information sharing and a more competitive banking structure. It is in this light that the current study sees ability of SMEs to access financial services as critical to SMEs growth and contribution to economic growth and development in Nigeria. In relation to SMEs financing, Ogbuanu, Kabuoh and Okwu (2014) suggest that SMEs financing is a source of employment, competition, economic dynamism, and innovation with capacity to stimulates sustainable economic growth and development.

Furthermore, Evbuomwan, Ikpi, Okoruwa, and Akinyosoye, (2012), in a study on Preferences of micro, small and medium scale enterprises to financial products in Nigeria using Survey data. They found that $75.7 \%$ of the respondents relied mostly on own funds to finance their businesses, the frequency analysis indicated that inadequate fund/working capital was the most mentioned problem with a percentage share of $60.7 \%$ followed by the problem of poor power supply/inadequate infrastructure which took $55.7 \%$. It was therefore, not surprising that $86.1 \%$ of the respondents would want the SMEs equity investment Scheme to continue. However, $64.7 \%$ would prefer loan so they can be in full control of their businesses, while only $15.7 \%$ preferred equity. The policy height of their study is that credit programmes that will take cognisance of the peculiarities of SMEs in Nigeria be intensified so as to increase their access to funds in view of their prevalence and potential contribution to the economy.

Igwe, Ogundana, Egere and Anigbo (2018), in a survey study, considered the factors affecting the investment climate, SMEs productivity and entrepreneurship in Nigeria. They found that infrastructure is one of the five key causes of low investment and productivity in Nigeria's SMEs. Accordingly, since investment and productivity are essential for economic growth and SMEs are the largest employers of labour in most developing economies, the issue of infrastructure investment cannot be overemphasized.

Obokoh \& Goldman (2016), also investigates the issue of infrastructure deficiency and the performance of small-and medium-sized enterprises in Nigeria's liberalised economy following a survey of some SMEs. The findings from the study suggest that infrastructure deficiency negatively impacts the profitability and performance of SMEs, due to the high cost incurred by SMEs in the self-provision of infrastructure and challenges encountered in distribution of their finished goods by way of transportation. This goes to buttress the cost cushioning effect of efficient and effective infrastructure in an economy, and that state provided infrastructure translate to giving entrepreneurs incentive for innovation and contribution to national development.

The ultimate in the development of SMEs in an economy is to see them grow into earning foreign exchange for the country through the exports of their finished products. In this respect, Babatunde, (2017) did a study on the export propensity and intensity of Nigerian SMEs. The study shows that firm age, labor productivity, access to loan and infrastructure are robust determinants of export propensity. Indeed, the Nigerian SMEs cannot favourably compete in the international market places if they are not able to keep cost under control. Ability to keep cost as low as possible is a measure of their efficiency and this efficiency can be enhanced if publicly provided infrastructure are functional and their employees productivity is enhanced.

One important infrastructure that has been adjudged critical for SMEs productivity is Power infrastructure. In this respect, Muhammed \& Yusuf (2017), examines the impact of quality electricity services on the Performance of Manufacturing SMEs in Nigeria using a survey method. The result from the study shows that electricity accounts for about $50 \%$ of the variances in the productivity of manufacturing SMEs in Nigeria. This reflect in the SMEs ability to maximize capacity, create needed jobs and remain in business. The sustainability of SMEs and the aspiration of the country to emerge in to one of the top 20 economies in the world hangs on functional infrastructure provision. Other studies in line with this position include: Okpara \& Kabongo, (2009); Adeolu, (2017); Akuru \& Okoro (2014).

Furthermore, most SMEs have small capital base and for this reason are located in remote and rural area 
where land acquisition is cheap and less cumbersome. However, they will have to contend with bad road and transport infrastructure in giving their finished products place value. In this regards, Omotayo (2018), in a study on sustainable intra-country transportation system: a panacea for African regional economic integration, examined the scope of African's regional economic integration and the role of transport infrastructure, domestic trade, trade facilitation, intra-African trade, market competitiveness, policies and planning, and regional economic communities. He suggests that instead of soliciting for funds outside the continent, African countries should look into ways of engaging in trade among themselves. He argued that trade and transport barriers lessen the competitiveness of locally manufactured goods and that a sustainable intra-country transport infrastructure has an immense impact on macroeconomics and development, therefore, it is an irreplaceable factor for wider economic integration.

\section{Theoretical Frame}

The theoretical basis for the consideration of the nexus between infrastructure and SMEs productivity can be situated within the context of the neoclassical paradigm to the extent that infrastructure is considered as capital and endogenous to growth process.

This study considered the theoretical stance in respect of this nexus from two perspectives. First, some school of thought aligned with the argument that infrastructure generally promotes growth as a cost reducing input. Second, other schools of thought are of the opinion that there is an opportunity cost to economic growth. Indeed, this is evident across economies just like the outcome of the other school of thought.

Accordingly, economic theory identifies channels through which infrastructure can impact on SMEs and eventually economic growth. Infrastructure may simply be regarded as a direct input into the production process and, hence, serve as a factor of production. Infrastructure may be regarded as a complement to other inputs into the production process, in the sense that its improvements may lower the cost of production or its deficiency may create a number of costs for SMEs. Infrastructure may stimulate a number of positive gains to SMEs. For example, efficient electricity infrastructure can allow for optimal capacity utilisation, efficient transportation and communication infrastructure can extend market frontiers for SMEs and also add place value to their products, skill acquisition centers can raise the managerial acumen of the SMEs entrepreneurs, hence greater productivity. Infrastructure investment can also boost aggregate demand through increased expenditure during construction, and possibly during maintenance operations. Government might attempt to activate this channel by investing in specific infrastructure projects with the intention of guiding private-sector investment decisions (Fedderke \& Garlick, 1995).

\section{Methodology}

The error correction methodology is employed for this study. The reason being that most economic time series are difference stationary and a regression of these series in their levels is bound to produce misrepresenting results. However, a linear combination of two or more I(1) series may be stationary suggesting that such series are cointegrated (Engle and Granger 1987). Accordingly, this linear combination describes a cointegrating equation with cointegrating trajectory of weights depicting the long-run relationship between the series. Given a long run relationship, an error correction mechanism (ECM) does exist among the series such that if any of the series departs from the long run equilibrium relationship, such series will eventually return to equilibrium. Cointegration allows long-run equilibrium to be restored gradually through a series of partial short-run adjustments. The partial short run adjustment is referred to as ECM.

\section{Model Specification}

This study employed time series on selected infrastructure and SMEs output in Nigeria over the period 1981. Adapting the model specified in an earlier study by Owolabi, (2015) in which gross fixed capital formation (GFCF), a measure of infrastructure investment was the regressor and gross domestic product (GDP) was the regressand. The model was specified as:

$$
\operatorname{LnGDP} P_{t}=\beta_{0}+\beta_{1} \operatorname{LnGFCF}_{t}+U_{t}
$$

The equation (3.1) is adapted bearing in mind the theoretical frame for this study and the following model specified in line with Engle and Granger two-steps approach.

$$
G D P_{t}=\beta_{0}+\beta_{1} \text { Wat }_{t}+\beta_{2} \text { Tran }_{t}+\beta_{3} \text { Elect }_{t}+U_{t}
$$

Given that all the variables in (5.2) are I(1) and integrated, the error correction model is thus:

$$
\Delta L n G D P_{t}=\lambda_{0}+\lambda_{1} \Delta \text { LnWat }_{t}+\lambda_{2} \Delta \text { LnTran }_{t}+\lambda_{3} \Delta \text { LnElect }_{t}+\alpha \hat{\varepsilon}_{t-1}+V_{t}
$$

Where: LnGDP $=$ Natural log of GDP at current basic prices

$\begin{array}{ll}\text { LnWat } & =\text { Natural log of Water/sanitation /sewerage infrastructure output } \\ \text { LnTran } & =\text { Natural log of Transport infrastructure output } \\ \text { LnElect } & =\text { Natural log of Electricity infrastructure output } \\ U_{t} & =\text { Error term }\end{array}$




$$
\begin{array}{ll}
\hat{\varepsilon}_{t-1} & =\text { Lagged residual from }(5.2) \\
\alpha & =\text { Speed of adjustment parameter } \\
V_{t} & =\text { White noise residual }
\end{array}
$$

Theoretical and recent empirical position suggests that the variables in our model are expected to take on positive sign as each of the right hand side variable is regarded as being capital in nature and would serve to reduce cost for the SMEs and enhance productivity, profitability and growth of SMEs in the country.

\subsection{Data}

This study utilised secondary time series on the variables in the model for the Nigerian economy over the period 1981 to 2017 . The data were sourced from the Central Bank of Nigeria (CBN) 2017 statistical bulletin. The variables are as defined in section (5)

\section{Model Estimate}

The estimation was preceded by necessary preliminary tests such as unit root test to ascertain the stationarity status of the time series. The unit root test result is as presented on table 6.1.1

Table 6.1.1: Unit root test

$\begin{array}{lllllll}\text { Variables } & \text { ADF Stat } & 1 \% \text { C. V } & \text { I(d) } & \text { P. P stat } & 1 \% \text { C.V } & \text { I(d) } \\ \text { SMEs Output } & -12.14 & -4.0217 & \text { I(1) } & -9.45 & -4.0204 & \text { I(1) } \\ \text { Water output } & -14.17 & -4.0208 & \text { I(1) } & -7.94 & -4.0199 & \text { I(1) } \\ \text { Transport Output } & -5.60 & -4.0200 & \text { I(1) } & -9.88 & -4.0191 & \text { I(1) } \\ \text { Electricity Output } & -13.48 & -4.0203 & \text { I(1) } & -34.96 & -4.0201 & \text { I(1) }\end{array}$

The unit root test indicates that the series are all integrated of order one, meaning that a model of their combination would result in cointergrating relationship. (Engle and Granger, 1987) This makes error correction methodology applicable.

Table 6.1.2: Step 1 Estimate, dependent variable is SMEs Output

$\begin{array}{lllr}\text { Variable } & \text { Coefficient } & \text { t-Statistic } & \text { Prob. } \\ \mathrm{C} & 2724778 & -0.16 & 0.8696 \\ \text { Elect } & -7.71 & 0.99 & 0.3232 \\ \text { Tran } & 16.60 & 1.59 & 0.1144 \\ \text { Wat } & 356.86 & 3.15 & 0.0020 \\ \mathrm{R}^{2} & 0.3183 & \text { F-Stat }=22.88 & \mathrm{DW}=2.10\end{array}$

Source: Authors' computation

It is necessary to check that the regression is not spurious. This is so, as Durbin-Watson statistic is greater than the coefficient of determination $\left(\mathrm{R}^{2}\right)$. Residual diagnostics indicates that the residual from the model is homoscedastic and serially uncorrelated following the ARCH test (appendix D) and Durbin-Watson statistic. The model has a good fit and is statistically significant at $1 \%$ as indicated by Fisher's statistic. The least square estimate presented in table 4.3.2 suggests that water and transport infrastructure have the potentials to promote SMEs output but only water infrastructure did so significantly over the period investigated. Electricity infrastructure impeded SMEs output but not significantly over the same period. The coefficients of the infrastructure variables indicate that one-point increase in transport and water infrastructure led to about 17 and 367 points rise in SMEs output respectively while one-point increase in electricity infrastructure led to about 8 points decline in SMEs output. Altogether, productivities in the water resources, transport and electricity sectors account for about $32 \%$ of SMEs output in the country.

The second step of the Engle and Granger two-steps approach entails taking the lag of residual from the estimate in the first step and estimate as in equation (3.3). This is presented in table 4.3.3.

Table 6.1.3: Step 2 Estimate, dependent variable is deference of logSMEs output

\begin{tabular}{lcrr} 
Variable & Coefficient & t-Statistic & \multicolumn{1}{c}{ Prob. } \\
$\mathrm{C}$ & 0.060122 & 3.454052 & 0.0007 \\
$\mathrm{D}$ (Elect) & -0.159277 & -2.634673 & 0.0093 \\
Dlog(Tran) & -0.050479 & -1.063090 & 0.2895 \\
Dlog(Wat) & $2.02 \mathrm{E}-06$ & 0.538025 & 0.5914 \\
$\quad \hat{\varepsilon}_{t-1}$ & $-7.33 \mathrm{E}-09$ & -1.810091 & 0.0724 \\
$\mathrm{R}^{2}$ & 0.2369 & & \\
F-Stat & 11.26 & & \\
Dw-Stat & 2.17 & & \\
\multicolumn{2}{r}{ Source: Authors ' computation }
\end{tabular}

The short run and long run relationship between SMEs output and the selected infrastructure were investigated using error correction mechanism. Particularly, electricity infrastructure impacted most negatively 
and significantly on SMEs output with a unit change in electricity output causing SMEs output to drop by about 0.2 units in the short run. The contribution of water resources and transport infrastructure have not been significant on SMEs productivity. The error correction term (ECT) took on negative sign as expected and is statistically significant. The ECT indicates that about 7.33E-09 of the disequilibrium between selected infrastructure and SMEs output in the economy is being restored annually. This implies that SMEs output and the selected infrastructure are cointegrated meaning that shot run disequilibrium between will be restored on the long run with annual speed of adjustment given by the coefficient of ECT. Residual diagnosis accepted the null hypothesis of homoscedastic and rejected the null of serial correlation following the ARCH and Durbin-Watson test respectively. Stability test on the ECM following the CUSUM procedure indicates that the model is stable as the CUSUM is statistically significant at 5\% significance level.

\subsection{Discussion of Result and Policy Implications}

The result from this study revealed that more needs to be done by the government and relevant stake holders in raising the infrastructure stock of the country for greater efficiency and productivity of the Nigerian economy. The existence of cointegration between infrastructure and SMEs output suggests that with appropriate policies, the activities of the SMEs can be galvanised for job and wealth creation, poverty alleviation and increased revenue base for the country. Water resources sanitation policy currently being worked upon, if well implemented, can further enhance the contribution of water resource infrastructure to SMEs productivity in the country. The inadequacy of electricity infrastructure in the country has conferred the greatest cost to the SMEs as found by this study. The government need to come up with policies which will allow for optimal mix of the various sources of electricity generation that are available in the country. The country is currently harnessing its potentials in the hydro and thermal sources. It's time to encourage the use of solar, wind as well as nuclear energy in a greater dimension in the country going forward.

\section{Conclusion}

This research investigates the impact of infrastructure on productivity of small and medium enterprises in Nigeria over the period 1981 to 2017. SMEs are critical for the achievement of macroeconomic goals of growth and employment generation as well as the desire to diversify the Nigerian economy. They also hold the key to the emergence of new generation of entrepreneurs and innovations. The conclusion based on the findings from this study is that the output of SMEs in the country has been constrained by infrastructure gap and this has limited the growth capacity of the Nigerian economy. The dynamics between SMEs output and infrastructure gives an optimistic outlook for the future as touching the potential of infrastructure-SMEs nexus to serve as the engine of growth for the Nigerian economy. This is because the duo co-integrate and follow an error correcting mechanism. Policies that will ensure that the SMEs play their roles must be hatched. The government need to, in the face of dwindling resources, consider alternate ways of raising the infrastructure stock of the economy. For instance, the public private partnership (PPP) formula might be an option for boosting infrastructure stock in the country. Infrastructure concession is also another option within the PPP framework for raising infrastructure stock in an economy. Tax policy of the government can also be softened towards the SMEs so as to give them the initial push. The government can also by way of policy, due to scarcity of resources to provide all needed infrastructure at a go, prioritise on the infrastructure that confers the greatest cost on the SMEs by popular demand from them. The government may consider creating SMEs zones in every State of the country and provide needed infrastructure within the zone such that SMEs can enjoy economies of agglomeration.

\section{Acknowledgement}

We acknowledge the Central Bank of Nigeria for data obtained from its archives in carrying out the empirical analysis for this study.

\section{References}

Adeolu, A. M. (2017). Improving The Institutional Environment for SME Success in Nigeria

Akuru, U. B., \& Okoro, O. I. (2014). Economic implications of constant power outages on SMEs in Nigeria. Journal of Energy in Southern Africa, 25(3), 47-61.

Aschauer, D. A. (1989). Is Public Expenditure Productive? Journal of Monetary Economics, 23: 177-200.

Babatunde, M. A. (2017). Export propensity and intensity of Nigerian SMEs. Journal of Small Business \& Entrepreneurship, 29(1), 25-55.

Beyene, A. (2002). Enhancing the Competitiveness and Productivity of Small and Medium Scale Enterprises (SMEs) in Africa: An Analysis of Differential Roles of National Governments through Improved Support Services.

Canning D. and Pedroni P. (1999), "Infrastructure and Long Run Economic Growth", Center for Analytical Economics Working Paper No. 99-09, Cornell University. 
Dosumu, O., Hussain, J., \& El-Gohary, H. (2017). An Exploratory Study of the Impact of Government Policies on the Development of Small and Medium Enterprises in Developing Countries: The Case of Nigeria. International Journal of Customer Relationship Marketing and Management (IJCRMM), 8(4), 51-62.

Engle, R. F., \& Granger, C. W. (1987). Co-integration and error correction: representation, estimation, and testing. Econometrica: journal of the Econometric Society, 251-276.

Evbuomwan, G. O., Ikpi A. E., Okoruwa, V. O. and Akinyosoye, V. O. (2012). Preferences of Micro, Small and Medium Scale enterprises to Financial Products in Nigeria. Journal of Agricultural Economics and Development. Vol. 1(4). October 2012. Available online at http://academeresearchjournals.org/journal/jaed. pp. $80-98$

Fatai, A. (2011). "Small and Medium Scale Enterprises in Nigeria: The Problems and Prospects" Retrieved January15 from www.thecje.com/journal/index.php/economicsjournalM /article

Fedderke, J., \& Garlick, R. (1995). Roads to Equality: Wealth Distribution Dynamics with Public-Private Capital Complimentarity. LSE Discussion Paper.

Igwe, P. A., Ogundana, A. N. A. O. M., Egere, O. M., \& Anigbo, J. A. (2018). Factors affecting the investment climate, SMEs productivity and entrepreneurship in Nigeria. European Journal of Sustainable Development, $7(1), 182-200$.

Kessides, C. (1993). The Contributions of Infrastructure to Economic Development: A Review of Experience and Policy Implications, 213. World Bank Publication.

Muhammed, A., Abdulraheem, I., \& Yusuf, I. (2017). Impact of Electricity Service Quality on the Performance of Manufacturing SMEs in Nigeria. Journal of Business and Social Review in Emerging Economies, 3(1), $1-10$

National productivity Centre (2009). Effect of Power Supply on the Productivity of Micro, Small and Medium Scale Enterprises (MSMEs) in Nigeria. National Productivity Centre. Publication.

Obokoh, L. O., \& Goldman, G. (2016). Infrastructure deficiency and the performance of small-and mediumsized enterprises in Nigeria's Liberalised Economy. Acta Commercii, 16(1), 1-10.

Okhankhuele, O. T. (2017). Effect of small and medium scale enterprises on economic growth in Nigeria. Journal of Research in National Development, 15(1).

Ogbuanu, B. K., Kabuoh, M. N and Okwu, A. T. (2014). Relevance of Small and Medium Enterprises in the Growth of the Nigerian Economy: A Study of Manufacturing SMEs. International Journal of Research in Statistics, Management and Finance. Vol. 2. No. 1. October 2014. ISSN PRINT: 2315-8409, ONLINE: 2354-1644. pp. 180-191.

Okhankhuele, O. T. (2017). Effect of small and medium scale enterprises on economic growth in Nigeria. Journal of Research in National Development, 15(1).

Okpara, J. O., \& Kabongo, J. D. (2009). An empirical evaluation of barriers hindering the growth of small and medium sized enterprises (SMEs) in a developing economy. African journal of business and economic research, 4(1), 7-21.

Okpara, J. O. (2011). Factors constraining the growth and survival of SMEs in Nigeria: Implications for poverty alleviation. Management Research Review, 34(2), 156-171.

Adenegan, K. O., Fagbemi, F., Osanyinlusi, O. I., \& Omotayo, A. O. (2018). Impact of the Growth Enhancement Support Scheme (GESS)'On Farmers' Income in Oyo State, Nigeria. The Journal of Developing Areas, $52(1), 15-28$.

Owolabi-Merus, O. (2016). Infrastructure Development and Economic Growth Nexus in Nigeria. International Journal of Academic Research in Business and Social Sciences, 5(1).

Oyelola, O. T., Ajiboshin, I. O., Raimi, L., Raheem, S., \& Igwe, C. N. (2013). Entrepreneurship for sustainable economic growth in Nigeria. Journal of Sustainable Development Studies, 2(2).

Perkins, P., Fedderke, J., \& Luiz, J. (2005, June). An Analysis of Economic In frastructure Investment in South Africa. Suoth African Journal of Economics, 73 No 2, 211 - 228.

Romer. (1990). Endogenous Technological Change. Journal of Political Economy, 71-103.

Sanchez-Robles, B. (1998). Infrastructure Investment and Growth: Some Empirical Evidence. Contemporary Economic Policy, 98-108.

Sani, B.M. (2001). 'The Collapse of industries in Kano: Causes and Solutions". Paper presented at joint Annual general meeting of manufacturers Association of Nigeria. Kano.

Schumpeter, J. A. (2006). History of economic analysis. Routledge.

The Guardian Newspaper July $8^{\text {th }} 2016$ pages $1 \& 6$.

Thorsten B. \& Demirguc-Kunt A. (2006), Small and medium-size enterprises: Access to finance as a growth constraint. Journal of Banking \& Finance, Volume 30, Issue 11Pages 2931-2943. https://doi.org/10.1016/j.jbankfin.2006.05.009

Todaro, M. P., \& Smith, S. C. (2004). Economics, Institutions, and development: A Global perspective.

Vivien, F., \& Nataliya, P. (2011). Nigeria's Infrastructure: A Continental Perspective. Policy Research Working 
Paper Series 5686, RePEc.

Wolassa, L. K. (2012). Infrastructure Investment and Economic Growth In South Africa: A Granger Causality Analysis. African Development Bank Group. 